\title{
TWENTY YEARS' WORK
}

IN

\section{THE SAMARITAN HOSPITAL, 1857-1877: \\ Shortly Revierved, Dec. I2th, 1877 .}

By T. S P E N C E R E L L S, F. R.C.S., Consulting-Surgeon to the Hospital.

Gentlemen,- - The operation I have just performed is the last I shall undertake in this Hospital, unless I do another next Wednesday, the rgth. There have been a few parietal and omental adhesions; but you have seen that a very few minutes-hardly more than a quarter of an hour-have been enough to complete the whole process, in complete silence, and without any hurry. Dr. Tweedie, one of our oldest physicians, but as young and active, apparently, as ever, has watched this proceeding with as much interest as a boy. The two cases I did last week you will see presently; one done the week before, two others by Dr. Bantock and Mr. Thornton, and a patient in process of recovery after draining a renal cyst-all encouraging results of less than a month's work.

It is exactly twenty years since I made my first attempt to perform ovariotomy. It was in this hospital, but not in this building. At that time (1857), we had hardly undergone the process of evolution from the dispensary into the hospital. We had a small house in Orchard Street, which was pulled down several years ago. On the ground floor were an office and a waiting-room, and a dispensary downstairs ; on the first floor, the patients waited in the front room, and were attended to in the back. On the second floor, there was room for a matron, and another for a resident house-surgeon, whose chief occupation was in bandaging the ulcerated legs of a crowd of out-patients. On the third floor, there were attics, one of which was occasionally made use of for an in-patient. I believe that up to 1855 or 1856 there had scarcely ever been an in-patient.

I began work in London in 1853 , and in the following year joined the hospital. Dr. Savage, now our senior consulting physician, is the only one of the present staff who was then connected with it. I did nothing but out-patient work in 1854 , and in January 1855 went off to the Crimea. After my return in 1856, I resumed the out-patient work. Snow Beck, Graily Hewitt, and Priestley had joined the staff, so had Routh and Wright; and we began to hope for something more than dispensary work. By arrangement with the matron, a bed could be occasionally obtained in an attic. Snow Beck, to the surprise of all of us, cured a vesico-vaginal fistula by the actual cautery; and he tapped an ovarian cyst and tried to inject it with iodine, with terrible result to the poor girl and (as he often told me afterwards) with deep distress to himself. We did not often see cases of ovarian disease at that time, but they did appear occasionally. I had, in 1854 once assisted Baker Brown to perform ovariotomy, and had not been encouraged by the result. He himself, in 1857 , was very desponding about it. He had not operated since March 1856. He used to say "peritonitis would beat us", and he was returning to the treatment by tapping and pressure, iodine injections and bichloride of mercury. Of his first nine cases of ovariotomy, seven had died. His colleagues at St. Mary's Hospital strongly opposed him. He was even threatened with an inquest on his next fatal case. And it now appears, by his own book on Ovarian Dropsy, that, between March 1856 and October 1858 (after my second successful case), he did not operate once.

During the autumn of 1857 , a young woman was under treatment for what appeared to be an ovarian tumour on the left side. Various opinions were very confidently expressed that this could not be an ovarian tumour, because intestines could be felt in front of it. But I determined to see what it was, and in December 1857, exactly twenty years ago, I prepared for my first ovariotomy. We cleared out the waiting-room, got a bed there, and secured a nurse. Quite a crowd of visitors came. As soon as I opened the peritoneum, and it was proved beyond all doubt that the tumour was behind the intestines, I was in duced to close the wound and do nothing more. The patient recovered without any bad symptom, but died four months afterwards in St. Bartholomew's Hospital, when it was found that it was a tumour of the left ovary, which might have been removed quite easily. This was not encouraging for a beginner; but it attracted the notice of $\mathrm{Mr}$. Bullen of the Lambeth Workhouse, and he offered me a patient then in his infirmary, who had been tapped three times in Guy's Hospital and four times in the Lambeth Workhouse, iodine having been injected twice. As she was willing to face any risk, I did ovariotomy for her in February 1858. The pedicle was treated by whipcord ligature, the ends hanging out at the lower end of the wound, after the fashion of Clay, Bird, Brown, and the earlier ovariotomists. At that time we had a house-surgeon, Mr. Cooke, afterwards of Clovelly; and, greatly owing to his constant care, the poor girl recovered. She became a nurse in the hospital, went into service, then emigrated, and I heard of her several years afterwards married to the German overlooker of a large estate in Queensland, whose salary was $£ 240$ a year. Had ovariotomy not been performed, she must have died in 1858 a pauper in a workhouse.

Between this first case in February 1858 and the second in August of the same year, we had left the old house and removed here, and the second operation was done precisely where so many have been done since, and where I operated just now. The third case was in the following November, and happily all the three women recovered. Had they died, such was the state of professional opinion at that time, the progress of ovariotomy might have been sadly retarded, if not stopped. I could occupy far more time than you could spare if I were to go over in detail the cases of successive years, tell you how each step of the operation has been gradually modified, how all the details of the nursing and after-treatment have been gradually brought to their present stage, and how, the confidence of the profession having been obtained, cases have multiplied faster than our means of treating them have been provided. But I may just show you in a table the results of the twenty years' work, which, with varying fortune from year to year, taken in a series of five years or of ten years, show a gradually increasing success and a diminishing mortality.

\begin{tabular}{c|c|c|c} 
Years. & Cases. & Recoveries. & Deaths. \\
\hline 1858 & 3 & 3 & 0 \\
1859 & 6 & 4 & 2 \\
1860 & 2 & 1 & 1 \\
1861 & 6 & 3 & 3 \\
1862 & 13 & 10 & 3 \\
1863 & 16 & 11 & 5 \\
1864 & 14 & 11 & 3 \\
1865 & 17 & 13 & 4 \\
1866 & 14 & 9 & 5 \\
1867 & 21 & 17 & 4 \\
1868 & 31 & 24 & 7 \\
1869 & 21 & 14 & 7 \\
1870 & 24 & 17 & 7 \\
1871 & 26 & 18 & 8 \\
1872 & 30 & 23 & 7 \\
1873 & 34 & 25 & 9 \\
1874 & 29 & 20 & 9 \\
1875 & 28 & 20 & 4 \\
1876 & 40 & 36 & 3 \\
1877 & 28 & 25 & 99 \\
Total.. & 403 & 304 &
\end{tabular}

Now let us see how far increasing experience has affected the proportion between recoveries and deaths in successive years. A glance at the table will show you how this varies in the several years; but we want larger numbers for anything like accurate statistical conclusions. This we may, perhaps, gain by grouping the cases together in series of five years. I have done this, and here is the result.

First five years

First five years

Third five years Cases.

Fourth five years

$\begin{array}{rrr}. & 30 & 3 \\ . & 82 & . \\ . . & \mathbf{1 3 2} & . \\ . . & 159 & . .\end{array}$

Recoveries.

$\begin{array}{ll}21 \\ 6 \mathrm{r} \\ & 96\end{array}$

96

Deaths.

9

If we take the last two years only ( 1876 and 1877 ), we find sixtyeight cases, with sixty-one recoveries and only seven deaths : a mortality barely exceeding ro per cent.

Or, putting the facts in another form, we may say, in the first five years about one in three died; in the second and third five years, about one in four died; in the fourth five years, about one in five died; but in the last two years only about one in ten died. It scarcely requires a moment's consideration of these facts-indeed, I think the question may be considered as settled-to establish the conclusion that increasing experience has been accompanied by diminishing mortality.

In 1872 , I attempted to trace the progress of ovariotomy in its range through almost every civilised country, from its cradle in America to its adoption in Spain and Italy. A glance over our list of visitors, with their places of residence, in our visitors' book, gives us a curious insight into the wide-spread interest which the subject bas aroused, and some notion of the advanced intelligence and surgical enthusiasm of the present time. Every man who visits this hospital 
on operation-day must be more or less guided there not only by curiosity, but by some serious intention to acquire information which may be practically useful to him; and it is gratifying to think to what extent that information may be disseminated, and the amount of good it may be the means of enabling surgeons to do. The advantages of this hospital are far from being confined to its inmates, and the experience gained through them rapidly benefits their remotest sisters in suffering. It passes to them through the hands of men who have been attracted into this little cosmopolitan chamber from the widest points of surgical industry, where, in seeing for themselves, they can compare notes with their antipodean confrères, stimulate their ambition by contact, and fortify their memories with the materials of valuable and pleasant reminiscences. The strongest contrasts of physiognomy and temperament cluster round us ; and, with the rarest exceptions, even the most susceptible and excited yield to the influence of British calm, and carry away not only a lesson on surgery, but on the advantages of method and silence. The man from Chili or Buenos Ayres is side by side with another from Stockholm or St. Petersburg ; one from Texas or the Cape with another from Vienna or Paris. Hong Kong and Jeddo are seen on the stools mutually supporting themselves between Rome and New York; a quartet from Berlin, Santa Cruz, Naples, and Moscow crowd together; and sometimes may be witnessed a motley group from Malta and Munich, Venice and Vienna, Naples and New York, Copenhagen and Chicago, Singapore and Seville. Natives, colonists, and foreigners, all seek a place and find an equal welcome, and are free to carry away all the impressions and knowledge they can pick up. We admit any qualified man from any part of the world. All we stipulate is, that they shall not poison the patients, as we used to fear they occasionally did before January 1873 , when we established the rule that every visitor should sign the following declaration : "We, the undersigned, have not been to any post mortem examination nor any dissecting-room, nor attended any case of infectious disease, within the last seven days." I believe this precaution has been one of the means by which mortality has been lessened.

Since the earliest operations, when Baker Brown and Tyler Smith were among the visitors, many others who have since distinguished themselves in this operation, or who have used their influence in extending it, have visited us. We have had from France Nélaton, Ricord, Demarquay, Worms, Labbé, Pean, and many others ; from Germany, Stromeyer, Nussbaum, Olshausen, Grenser, Leopold ; from Belgium, De Roubaix; Howitz, Nicolaysen, and Sköldberg from Denmark, Norway, and Sweden ; Tracy of Melbourne, who was the first to do the operation in Australia ; Russians and Italians ; De Toca from Madrid ; and a host of our American brethren, from Marion Sims and Kimball to the last arrivals from Chicago and San Francisco who are here to-day, have all alike seen what we do and how we do it.

In speaking of ovariotomy in this hospital, and in preparing these tables, I have spoken of my own work alone. For many years, with an occasional rare exception, I did all these operations. Latterly, as the numbers have increased, and I have become consulting surgeon since the death of Sir William Fergusson, I have gradually made way for the two present surgeons, Bantock and Thornton; and, after the end of this year, they will do all the surgery, aided by two good menMeredith and Doran-who are in training for the work they may hereafter be called upon to do. Already the two surgeons have done sixty-five cases with only twelve deaths - a result of which any surgeon living might be proud; and we may reasonably hope for still better results. The antiseptic system is on its trial. We have not seen enough of it as yet in ovariotomy to warrant us in saying more than that the evident objection of operating in a chilly mist may be partially avoided; that no great harm is done by peritoneal absorption of carbolic acid; that dressings are simplified; and that hyperpyrexia is less to be feared. If further experience confirm all this, it will certainly be our duty to give our patients every advantage, even if it be but fractional. A lowering of mortality of one per cent. would reward us for any amount of trouble; and I am more hopeful of late, since the introduction of thymol as a substitute for the offensive and objectionable carbolic acid. Thymol has a very pleasant odour, and has no poisonous property. Dr. Burdon Sanderson tells me it is a hundred times more effective as a germicide than carbolic acid; and our former colleague Dr. Junker writes me from Berlin that Volkmann's results of trials with it, even in wuch weak solution as one part in two thousand of water, encourage us to hope that we shall soon be able to dispense altogether with our disagreeable but useful servant carbolic acid.

I must not let you suppose that ovariotomy has been the only surgical work done here. Putting aside such things as uterine polypi, epithelioma of the cervix uteri, and various diseases of the external genital organs, we have had a great many cases of vesico-vaginal fistula and of ruptured perinæum, and have, I think, greatly improved the operative procedures. Many mammary and other tumours have been removed; and several years ago, before the rules were very rigidly enforced which limit us to the admission of diseases peculiar to women, I had two interesting cases of the cure of amenorrhœa by surgical operation. One of the patients had a malignant tumour of her thigh, and I amputated at the hip-joint. She got quite well, and so did another patient after I removed half her lower jaw with a tumour of the bone. These, however, were mere episodes ; but they did serve some useful purpose by showing that the same care bestowed upon patients during and after other great operations is rewarded by the same encouraging results as in ovariotomy. An amputation of the thigh for hyperostosis of the tibia I did for one of my official patients in the Queen's household. She was a favourite old housemaid, who had made the beds of the princesses for several years, and the Queen was graciously pleased to express her desire that I should operate myself on her old servant. So I operated in this room, and the old pensioner seems likely to enjoy her retirement for many years to come. I pass over, as too large a subject for to-day, what we have done by the removal by gastrotomy of large uterine tumours, by draining ovarian cysts which could not be removed, by nephrotomy very lately, and, in a very interesting case now in the house, by draining a renal cyst under strict antiseptic precautions.

I have now only to add that, although my duty to my private patients prevents me any longer from acting here as one of the surgeons, neither my colleagues nor I wish that my position as consulting surgeon shall be purely honorary. We hope to arrange one day weekly-probably Friday, at two o'clock-when we propose to hold public consultations upon patients in the hospital, upon selected cases from the out-patients, and upon patients whom any of our professional brethren may bring for an opinion or may recommend for admission. A somewhat similar plan of public consultation has been carried on for some time at St. Bartholomew's Hospital on Thursdays, and I am assured these meetings are most instructive. The surgeons express their opinions freely and openly in the presence of the students, explaining the grounds of any difference of opinion. Here, of course, we have no young students, and the feelings of the patients must be carefully considered; but I hope, after a few trials, we may agree upon some plan which will be useful and interesting as well to our friends as to ourselves.

\section{DORSAL DISLOCATION OF THE HIP.}

THE patient in this case, a boy nearly ten years of age, was riding on a threshing-machine in motion, and fell between the engine and the water-barrel, the latter being some nine or ten inches from the ground. The boy was, it appears, rolled under the water-barrel in such a manner as to wrench his right thigh-bone out of its socket. On my being called to the patient, there was found to be considerable deformity of the back and outer part of the right thigh, which was nearly im. movable and directed across the lower third of the opposite thigh, the whole limb being inverted. Altogether, it was a typical case of dorsal dislocation. The right knee was rather bruised, but otherwise there were no external marks of injury. An attempt at reduction was made at the time, about three hours after the accident, but without the use of an anæsthetic. The method by extension and counterextension was first tried, but without success. Manipulation by Bigelow's method was then attempted, and with partial success, the head of the femur being got into the ischiatic notch, as evinced by the position of the limb, which was considerably improved, there being but slight inversion and a less amount of shortening, viz., about an inch. As the lad had suffered great pain from the attempts at reduction, it was not thought advisable to proceed further at the time; but, at a subsequent visit forty-eight hours after the accident, chloroform was administered, and the dislocation reduced almost instantaneously by simpiy manipulating after Bigelow's method; viz., by first flexing the thigh, then abducting it and rotating it outwards, when the head of the bone was heard to fall into its socket by a distinct snap.

This case is simple and uncomplicated, but it seems worthy of record from the fact that dislocations of the hip at an early age are comparatively unfrequent, and also from the fact that the dislocation was readily reduced by the method of manipulation, which is far easier and more manageable than the old method by extension and counter. extension, no apparatus of any kind being necessary for its accomplishment. Doubtless reduction would have been complete at the first attempt by that method, had chloroform been at hand. It may be added that the patient is progressing favourably, without a single bad symptom.

R. L. BATterbURY, M.B.Lond., Berkhamsted. 